\title{
Strengthening Techniques \& Failure Modes of RC Beam Strengthened Using Fibre Reinforced Polymer. A Review
}

\author{
Muhammad Imran, Nasir Shafiq, Ibrisam Akbar
}

\begin{abstract}
RC) beam using Fibre Reinforced Polymer (FRP) revealed as the most efficient material due to its various mechanical properties. The previous experimental studies conducted to discuss strengthening schemes for RC beam, based on the observed crack pattern and failure mechanism for strengthening RC beam. The development of crack formation on RC beams under loading identifies the mode of failure and strengthening scheme required, such as to increase the flexural capacity of RC beam; FRP is applied at the tension zone. Similarly, for shear and torsion strengthening FRP wraps are being applied at the faces of the beam. The studies have shown the high strength in shear and torsion is achieved by applying U-shape wrap. Full warp gives high strength in torsion strengthening but practically the application of full wrap on RC beam is impossible and required more in-depth study to propose practical solutions. However, the combined effects of flexure, shear and torsion have not been discussed yet. Therefore, the strengthening schemes from literature are combined to propose new strengthening scheme for RC beam under combine the action of flexure, shear and torsion. However, experimental data are required to validate the proposed scheme.
\end{abstract}

Index Terms - Crack, Flexure, FRP, Reinforced Concrete Beam, Strengthening, Shear, Torsion.

\section{INTRODUCTION}

$\mathrm{F}$ ibre Reinforced Polymer (FRP) has been used since 1980s as a useful material for strengthening Reinforced Concrete (RC) structural member. FRP is easy to apply, high strength to weight ratio, cost effective and required less maintenance [14]. FRP is being successfully applied to strengthening RC structural member like beam, slab, column, etc. In this study different problem and limitation for the strengthening RC beam are discussed.

Research has proven FRP for enhancing the ultimate load carrying capacity, ductility, deflection, post crack stiffness of $\mathrm{RC}$ beam tremendously. RC beams most of the time suffered

Manuscript received July 15, 2013. The author would like to thank for the graduate assistantship of the Universiti Teknologi

Muhammad Imran MSc. Student Dept. of Civil Engineering Universiti Teknologi PETRONAN $31750 \quad$ Tronoh, Malaysia (engrimran_ce@hotmail.com)

Nasir Shafiq Dept. of Civil Engineering Universiti Teknologi PETRONAS 31750 Tronoh, Malaysia (nasirshafiq@petronas.com.my)

Ibrisam Akbar Dept. of Civil Engineering Universiti Teknologi PETRONAS 31750 Tronoh, Malaysia (ibrisam_akbar@petronas.com.my). non-uniform loads which induce combine stress of flexure, shear and torsion. In previous studies the effects of flexure, shear and torsion on RC beam have been discussed individually and the relevant strengthening scheme has also been proposed based on experimental results. Most of the test was carried out under three point loading and four point loading $[1,3]$ for flexure and shear. Pure twisting loads applied for torsion [5-7]. In this review paper the available option for strengthening RC beam under flexure, shear and torsion is highlighted. There are several options available for strengthening RC beam using FRP, some of them were practically not applicable such as FRP full wrap on RC beam for shear and torsion strengthening [5-13]. These schemes must be refined to attain a suitable solution, which should also be practically sound. On the other hand after applying FRP on RC beam under different conditions, it is essential to understand the failure mechanism of FRP such as FRP rupture, de-bonding, etc. However, factor involves in debonding are concrete strength, type of wrap, the strength of the strip, number of wraps, reinforcement ratio, and epoxy used etc.

\section{A. Research Significance}

RC beams carry a variety of loadings such as flexure, shear and torsion simultaneously. The beams especially on bridges, where moving traffic changes with the traffic flow rate. While in the building loads transferred on beam from slabs are also not always uniform. These non-uniform loads cause combine effect of flexure, shear together with a torsion. Therefore in this paper the suitable strength scheme is highlighted together with elaboration the failure mechanism of FRP.

\section{B. Research Significance}

The objectives behind this study are, i) to highlight effective strengthening schemes for flexural, shear and torsion, ii) to gather the basic deformity and failure mechanism after strengthening of RC beams using FRP.

\section{FleXure Strengthening and Failure Mechanism of RC BEAM}

The most frequent failure mechanism in RC beams is a flexural failure under bending stresses. Most of the beams lose their design strength and durability as the load exceeds its 


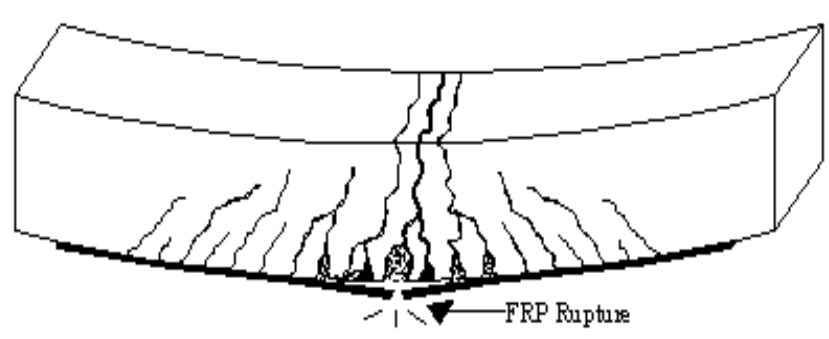

(a)

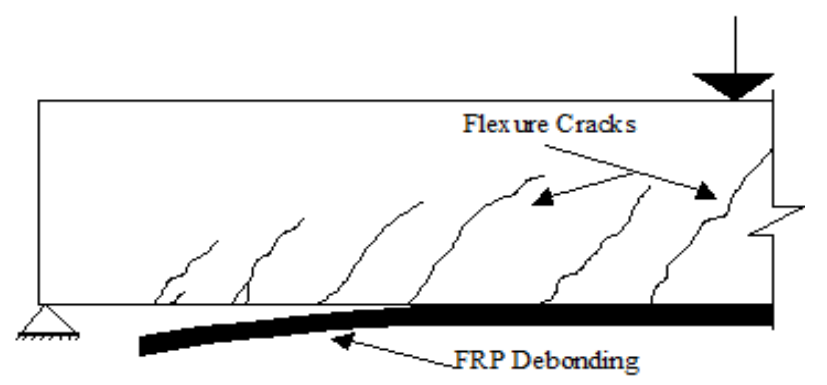

(c)

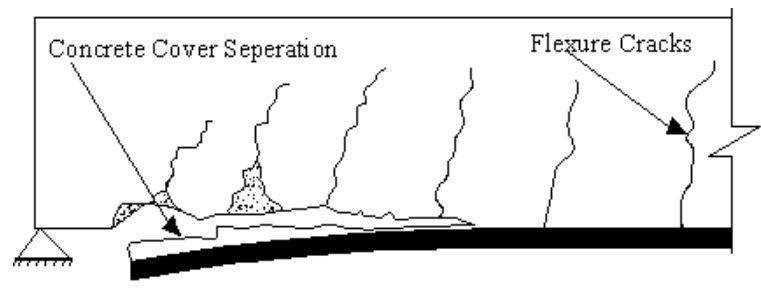

(b)

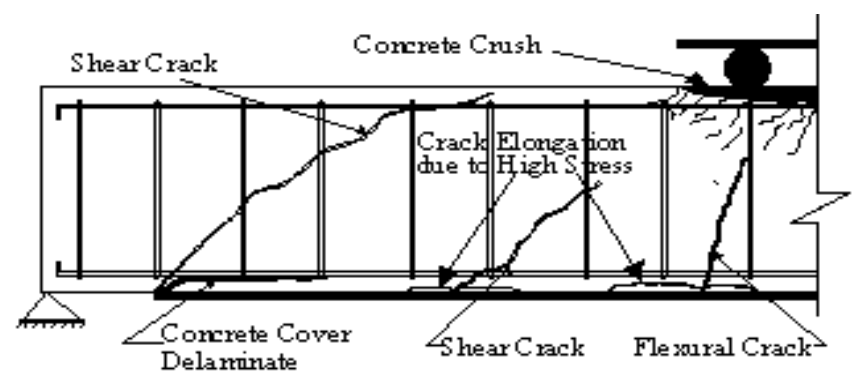

(d)

Fig. 1. Flexure cracks and failure mode of RC beam strengthened using FRP (a) FRP Rupture (b) Concerted Cover Detached with FRP (c) FRP De-bonding (d) Failure of RC beam by concrete crushing in compression zone shear cracks and interfacial de-bonding due to flexures-shear cracks [ 26, 27].

design capacity or when the new standards introduced, which invalidate the pervious specification.

It is found from different studies, that the compression zone of the RC beam is safer from failure as the tension zone used to be under pure bending, due to properties of concrete. The critical area for beam under bending stresses is a tension zone of the RC beam [14]. Mostly, the failure initiated by the development of crack from tension zone, and extended up to compression zone before reaching to failure [15]. These cracks usually start from the bottom of applied load, which indicates flexural failure. Therefore, numerous studies have proven that the application of FRP in the tension zone of the RC beam enhanced the flexure strength of RC beam tremendously [10,14, 16-24].

However, applying only FRP at the tension zone may cause de-bonding of the strip or premature failure as the cracks widen before reaching to ultimate load carrying capacity [25]. The RC beam strengthened using FRP failed due to various causes that involve concrete strength, reinforcement ratio, area of FRP, etc.

However, the most common type failure modes reported in the previous studies are as follows:

1) FRP rupture,

2) FRP and concrete cover separation,

3) FRP De-bonding,

4) Concrete Crushed at compression zone

5) Shear Crack,

6) Interfacial de-bonding at the end of plate and

7) De-bonding due to intermediate flexure-shear cracks as shown in figure. $1[26,27]$.

Therefore, the above failure mode of FRP occurred before reaching to ultimate strength due to various reasons which involve type of FRP, concrete properties, epoxy applied, etc. To avoid premature failure of RC beam U-Shape wraps have shown drastic improvement, which not only enhance the strength but also ductility of RC beam [10, 16, 19, 28, 29].

\section{Shear Strengthening and Failure MEChanism of RC BEAM}

Shear failure compared to flexural failure is more devastating due to sudden failure. Shear failure start occurring from the critical section at high shear zone near support. The failure is usually occurring without giving any alarming alerts. Therefore, shear failure considered to be more dangerous for structures than flexural failure [8, 27, 30, 31]. Shear force maximum at support and the diagonal cracks start from support to applied load. These diagonal cracks formed on either side or both sides together in RC beam and failure occurred by widen of shear cracks in RC beam [32].

Therefore, most experimental studies suggested, different FRP strengthening scheme to prevent shear failure in RC beam. For strengthening, FRP strips have used on the faces of the RC beam in previous studies [8, 10, 11, 31, 33-35]. These common types of FRP scheme have been used most frequently in the previous studies i) $90^{\circ}$ strips [figure 2] (a), ii) $45^{\circ}$ strip [figure 2 (b)] and iii) U-shape full wrap [figure 2 (c)], in the form of rigid or flexible FRP scheme[8, 10, 27, 31, 34-36].

It is revealed from previous studies that $90^{\circ}$ wraps were used most commonly in the experimental studies. The shear capacity enhances tremendously by applying $90^{\circ}$ FRP strip on the RC beam [33, 37].

Similarly, the $45^{\circ}$ wrap provides high strength and ductility 


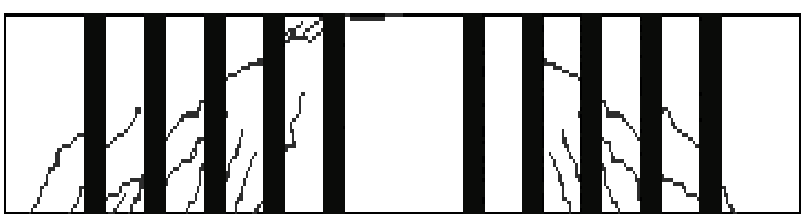

(a)

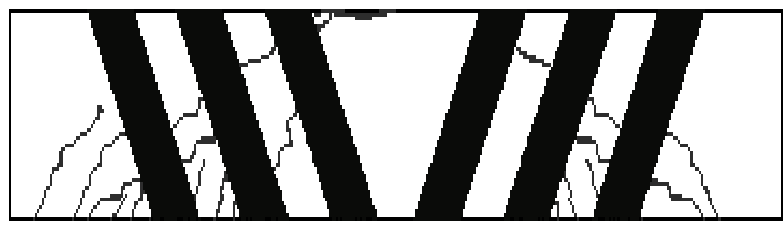

(b)

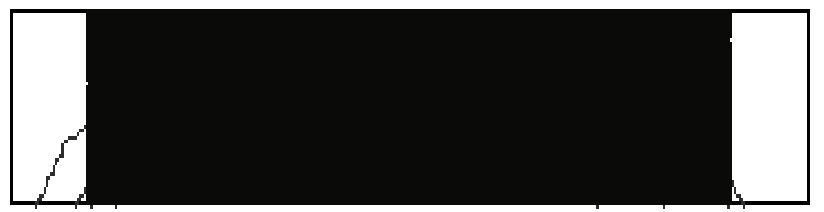

(c)

Fig. 2. (a) Shear Strengthening using $90^{\circ}$ strip, (b) Shear Strengthening using $45^{\circ}$ strip, (c) Shear strengthening using U-shape full wrap.

then the $90^{\circ}$ wrap [11, 33]. In some cases the full wrap also applied to observe the behaviour of RC beams and to increase experimental data. However, the strength achieved by applying full wraps to the sides of RC beam is much similar or less than $90^{\circ}$ wrap in strip [11, 33]. However, in some studies the higher strength attained with same wrapping system by adding end anchor [8, 29, 30].

In addition, the common dominating failure mechanisms in case of RC beam strengthened for shear using FRP are:

1) Shear Crack,

2) FRP rupture,

3) FRP Delamination,

4) FRP De-bonding with concrete cover as shown in figure. $3 \& 4$.

Nevertheless, the strength and failure mode of RC beam also depends on FRP spacing, shear span to effective depth ratio end anchorage for enhancing capacity up to $80 \%$ [11,

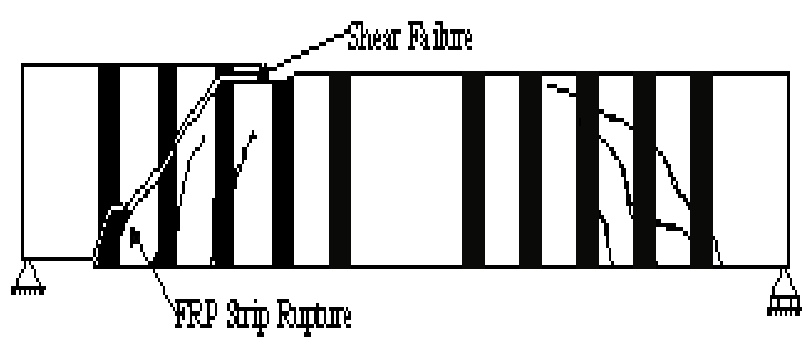

Fig. 3. Shear Failure of RC Beam Strengthened suing $90^{\circ}$ wraps by Rupturing of FRP due o large shear crack.

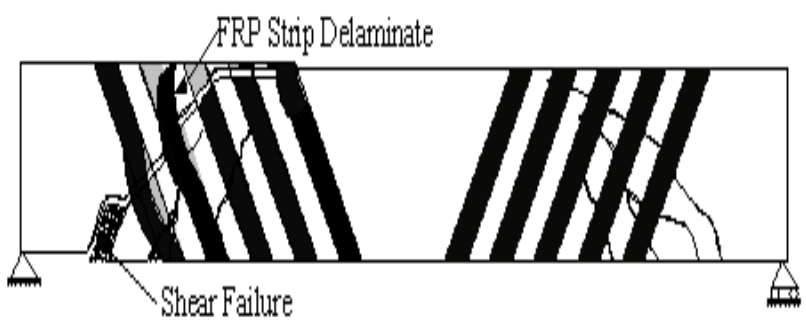

Fig. 4. Shear failure due to FRP delaminate with concrete cover.

38].

\section{TORSION StREngthening AND FAILURE MECHANISM OF RC BEAM}

The application of FRP has also shown significant enhance in the torsion strength of the RC beam. Different structural members due to varying loads, curved beam and mostly skewed girders of bridges frequently experience torsion loads. The strengthened RC beam using FRP contribute in enhancing ultimate torsion capacity, post cracking loads, angle of twist, and torsion moment capacity.

In previous studies the behaviour of RC beams are studied under torsion by applying pure twisting loads [5-7, 39-42].

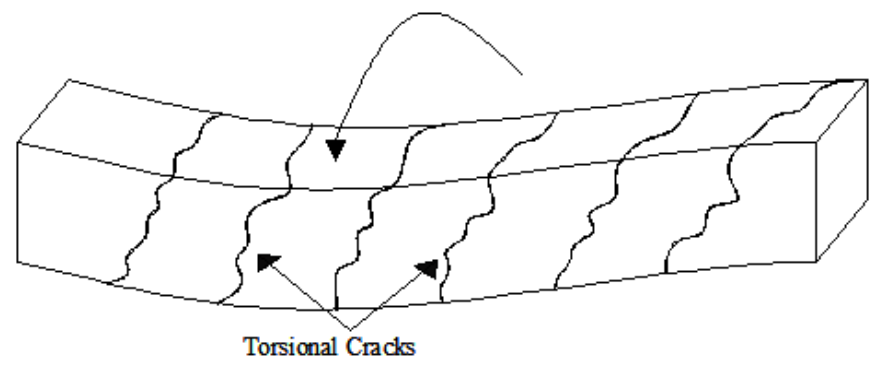

Fig..5 Cracks on Un-strengthened RC Beam due to pure torsion.

Basically, these loadings have been used only for testing and comparing experimental results with analytical results. However, pure torsion practically rarely exits [5, 43]. The study of torsion with flexure or shear is avoided due to complex behaviour and crack pattern. The cracks developed under pure torsion load observed more uniform and diagonally distributed on the whole surface of the beam as shown in figure 5.[44].

Therefore, the available strengthening options for torsion strengthening have found to be similar as shear strengthening schemes but the wraps applied around the beam such as $90^{\circ}$ U-shape / full wrap [figure 6 (a)], $45^{\circ}$ U-shape / full wrap [figure 6 (b)], full- [figure 6 (c)] [5-7, 39-42].

However, for torsion strengthening the scheme is develop to confined cracks and slows down the procedure of crack formation, crack widening and delaying failure of RC beam. For torsion strengthening the great emphasis found on full wrap scheme in previous studies, since the behaviour of pure torsion cause RC beam to twist and cracks formation appears 
on the full surface of the beam. Full wrap provides confinement to RC beam, avoid formation of cracks, enhanced post cracking load and distribute stresses evenly [5-

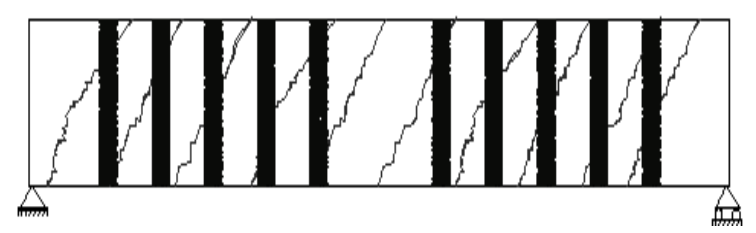

(a)

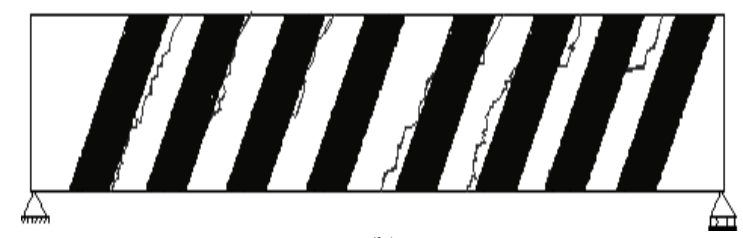

(b)

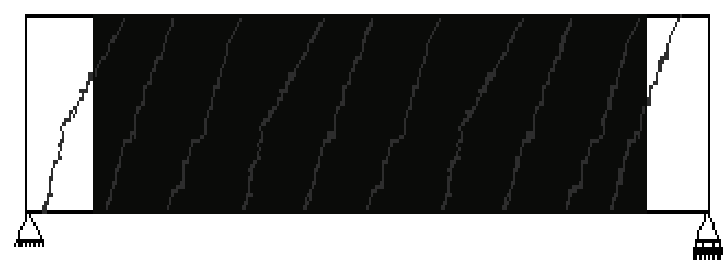

(c)

Fig. 6. (a) Torsion strengthening using $90^{\circ}$ wrap, (b) Torsion Strengthening using $45^{\circ}$ wrap, (c) Torsion strengthening using full wrap.

$7,12,40]$.

In some studies more than one also layer applied, which shown enhancement in torsion capacity more than $100 \%$ [7, 12, 40, 43]. Crack formation after full wrapping on RC beam have been found more uniformly spaced, which shows the uniform distribution of stresses after applying FRP [12, 40]. Nevertheless, most of the studies suggested the $90^{\circ}$ and $45^{\circ}$ FRP wrap on the RC beam, these schemes also enhance the torsion capacity of RC beam lower than full wrap but they are economical.

However, practically the use of a full wrap or full wrap in the form of strips is impossible [5], despite of a high strength achieved by applying a full wrap [5-7, 12, 40]. Therefore, the U-shape warp [figure 7] is also suitable for strengthening RC beam under torsion loading. The performance FRP U-wrap depends on spacing of wraps and bonding length [45]. The FRP U-shape wrap practically possible in application, but it gives lower strength than full wraps, but due to its practical implementation, it is recommended in most of the studies [12, 40].

However, the failure modes for torsion strengthened beams using FRP are reported as:

1) Shear Crack,

2) FRP rupture,

3) FRP Delamination,

4) FRP de-bonding with concrete cover due to high stress.

In figure 8 (a) the beam FRP ruptured as the concrete crushed. Similarly, the beam fails in de-bonding by tearing concrete

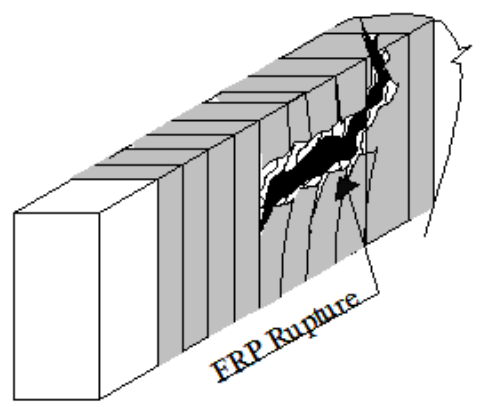

(a)

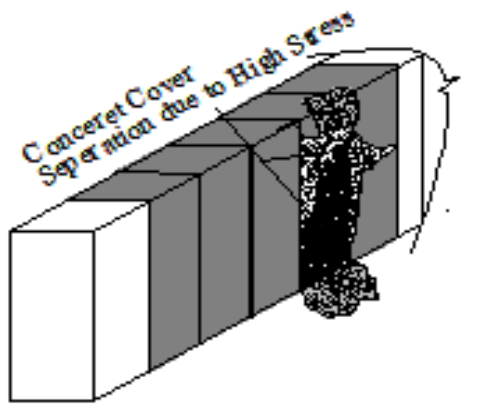

(b)

Fig. 8. RC beam strengthened using FRP (a) Concrete fail followed by rupturing FRP (b) FRP delaminate with tearing concrete cover due to high stresses.

cover with FRP as shown in figure 8 (b). These failures can be delayed, but they cannot be averted completely.

\section{Combined StRengthening And FAilure Mechanism of RC BEAM}

The RC beam mostly suffered under combine the action of flexural and shear, and most of the time under torsion due to load distribution or when the applied loads are eccentric [46]. Normally, shear start with small bending [32], whereas torsion starts when the shear force could not pass from shear centre. Since the uniform loads rarely exists in any structure. The first crack normally occurs in RC beam is due to bending stresses [47]. RC beam should not strengthen for a single effect, different failure modes may arise together. The formation of crack is very complex than individual behaviour of flexure, shear and torsion due to action of combine stresses simultaneously.

There are several studies available which discussed flexure and shear together [10, 27, 48, 49]. But the studies discussing combine effects of flexure, shear and torsion is hardly found [50]. Only a few studies recommend applying the FRP full wrap, U-shape wrap or FRP wraps with anchor to support RC beam under combine stresses together with enhance ultimate load carrying capacity under combine action [50-52].

\section{CONCLUSION}

Based on the previous studies of FRP has proven its 
promising ability for strengthening RC beams under flexure, shear and torsion. The proposed strengthening schemes are suitable for individual behaviour of RC beam. But for strengthening RC beam it should be considered, that mostly structures bear non-uniform loads. These non-uniform loads cause combined stresses of flexure, shear and torsion on RC beam. The combined effects are being ignored due to complication in behaviour and analysis. However, RC beam must be strengthened to resist the combined effect of loading, to avoid unpredicted failures of RC beams. Therefore, from the review of past experimental studies, it has been concluded that vast data is available for strengthening RC beams for flexure, shear and torsion, but combine effect found hardly from the study.

The cracks pattern indicates of expected failure mechanism. Based on crack pattern the failure mode can be identified and RC beam strengthened for the effected deficient mode. It is recommended that RC beam must be strengthened by applying FRP at the tension zone of the beam for flexural strengthening. CFRP strip is mostly used for shear strengthening due to rigidness they cannot warp which makes them less effective for torsion. Therefore, the strengthening schemes for shear and torsion found to be more similar in application of wrap on both faces inform of U-shape wrap to enhance shear as well as torsion capacity together with improving ductility. Combining both strengthening scheme, FRP strip at bottom and CFRP Ushape wrap can improving combine effect of flexure, shear and torsion. However, experimental investigation is required to validate proposed strengthening scheme. In addition, the failure of FRP is either due to rupturing of CFRP or debonding, despite of various factors involve in failure mode.

Furthermore, the experimental studies is required to applying different loadings, such as eccentric loads and these proposed schemes should be experimentally tested to analyse the effectiveness of these schemes under eccentric load since the uniform loads are hardly exist. Therefore, the different loading arrangement would give the better understanding of the cracking pattern under combined action and examine the effectiveness of proposed strengthening scheme on RC beam.

\section{ACKNOWLEDGMENT}

The author would like to thank lab technician for their continuous support, Head of Civil Engineering department and Universiti Teknologi PETRONAS for the graduate assistantship.

\section{REFERENCES}

III

[1] J. Dong, Q. Wang, D. He, and Z. Guan, "CFRP sheets for flexural strengthening of RC beams," 2011, pp. 1000-1003.

[2] D. E. Tonias, Bridge engineering: design, rehabilitation, and maintenance of modern highway bridges: McGraw-Hill, 1995.

[3] P. Perkins, Repair, protection and waterproofing of concrete structures: Taylor \& Francis, 1997.

[4] T. C. Triantafillou and N. Plevris, "Strengthening of RC beams with epoxy-bonded fibre-composite materials," Materials and Structures, vol. 25, pp. 201-211, 1992/05/01 1992.

[5] A. Ghobarah, M. N. Ghorbel, and S. E. Chidiac, "Upgrading Torsional Resistance of Reinforced Concrete Beams Using Fiber-
Reinforced Polymer," Journal of Composites for Construction, vol. 6, pp. 257-263, 2002.

[6] C. Constantin E, "Torsional strengthening of rectangular and flanged beams using carbon fibre-reinforced-polymers Experimental study," Construction and Building Materials, vol. 22, pp. 21-29, 2008.

[7] S. Panchacharam and A. Belarbi, "Torsional behavior of reinforced concrete beams strengthened with FRP Composites," 2002, pp. 111.

[8] K. Uji, "Improving shear capacity of existing reinforced concrete members by applying carbon fiber sheets," Transactions of the Japan Concrete Institute, vol. 14, pp. 253-266, 1992.

[9] M. J. F. Mohammad Reza Mohammadizadeh1*, and Hamid Reza Ronagh2, "Improving Torsional Behaviour of Reinforced Concrete Beams Strengthened with Carbon Fibre Reinforced Polymer Composite," ed, 2009.

[10] e. a. Tom Norris, "Shear and Flexural Strengthening of R/C Beams with Carbon Fibre Sheets," Journal of Structural Engineering, vol. 123, 1997.

[11] Z. Zhang and C.-T. T. Hsu, "Shear Strengthening of Reinforced Concrete Beams Using Carbon-Fiber-Reinforced Polymer Laminates," Journal of Composites for Construction, vol. 9, pp. 158-169, 2005.

[12] M. R. a. F. Mohammadizadeh, M. J., "Torsional Behaviour of High-Strength Concrete Beams Strengthened Using CFRP Sheets; an Experimental and Analytical Study," Scientia Iranica Transaction a-Civil Engineering, vol. 16, pp. 321-330, Jul-Aug 2009.

[13] A. K. Y. Hii and R. Al-Mahaidi, "Torsional strengthening of reinforced concrete beams using CFRP composites," ed.

[14] F. Bulavs, I. Radinsh, and N. Tirans, "Improvement of capacity in bending by the use of FRP layers on RC beams," Journal of civil engineering and management, vol. 11, pp. 169-174, 2005.

[15] A. N. Marco Di Ludovico, Andrea Prota, and Edoardo Cosenza, "Repair of Bridge Girders with Composites: Experimental and Analytical Validation," ACI Structural Journal, 2005.

[16] A. H. Al-Saidy, A. S. Al-Harthy, K. S. Al-Jabri, M. Abdul-Halim, and N. M. Al-Shidi, "Structural performance of corroded RC beams repaired with CFRP sheets," Composite Structures, vol. 92, pp. 1931-1938, 2010.

[17] Y. T. Obaidat, S. Heyden, O. Dahlblom, G. Abu-Farsakh, and Y. Abdel-Jawad, "Retrofitting of reinforced concrete beams using composite laminates," Construction and Building Materials, vol. 25, pp. 591-597, 2011.

[18] A. F. Ashour, S. A. El-Refaie, and S. W. Garrity, "Flexural strengthening of RC continuous beams using CFRP laminates," Cement and Concrete Composites, vol. 26, pp. 765-775, 2004.

[19] E. Ahmed, "Flexural performance of CFRP strengthened RC beams with different degrees of strengthening schemes," 2011.

[20] H. Pham and R. Al-Mahaidi, "Experimental investigation into flexural retrofitting of reinforced concrete bridge beams using FRP composites," Composite Structures, vol. 66, pp. 617-625, 2004.

[21] M. R. Aram, C. Czaderski, and M. Motavalli, "Debonding failure modes of flexural FRP-strengthened RC beams," Composites Part B: Engineering, vol. 39, pp. 826-841, 2008.

[22] E. David, E. Ragneau, and F. Buyle-Bodin, "Experimental Analysis of Flexural Behaviour of Externally Bonded CFRP Reinforced Concrete Structures," Materials and Structures, vol. 36, pp. 238-241, 2003.

[23] A. M. Okeil, S. El-Tawil, and M. Shahawy, "Flexural Reliability of Reinforced Concrete Bridge Girders Strengthened with Carbon Fiber-Reinforced Polymer Laminates," Journal of Bridge Engineering, vol. 7, pp. 290-299, 2002.

[24] M. Arduini and A. Nanni, "Behavior of precracked RC beams strengthened with carbon FRP sheets," Journal of Composites for Construction, vol. 1, pp. 63-70, 1997.

[25] B. Gao, J.-K. Kim, and C. K. Y. Leung, "Experimental study on RC beams with FRP strips bonded with rubber modified resins," Composites Science and Technology, vol. 64, pp. 2557-2564, 2004. J. Yao, J. Teng, and L. Lam, "Experimental study on intermediate crack debonding in FRP-strengthened RC flexural members," Advances in Structural Engineering, vol. 8, pp. 365-396, 2005. M. A. R. M. Z. Jumaat, M. A. Alam and M. M. Rahman, "Premature Failures in Plate Bonded Strengthened RC Beams with an Emphasis on Premature Shear: A Review," International 
Journal of the Physical Sciences, vol. Vol. 6(2), pp. 156-168, 2011.

[28] D. Jiangfeng, W. Qingyuan, H. Dong, and G. Zhongwei, "CFRP sheets for flexural strengthening of RC beams," in Multimedia Technology (ICMT), 2011 International Conference on, 2011, pp. 1000-1003.

[29] M. A. A. a. M. Z. Jumaat, "Eliminating Premature End Peeling of Flexurally Strengthened Reinforced Concrete Beams," Journal of Applied Sciences, vol. 9, pp. 1106-1113, 2009.

[30] M. Z. Jumaat and M. A. Alam, "Optimization of intermediate anchors to eliminate premature shear failure of CFRP laminate flexurally strengthened RC beams," Int. J. Phys. Sci, vol. 6, pp. 182-192, 2011.

[31] A. Li, D. Cheikhna, and Y. Delmas, "CRFP Contribution to Shear Capacity of Strengthened RC Beams," Engineering Structures, vol. 23, pp. 1212-1220, 2001.

[32] B. Täljsten, "Strengthening concrete beams for shear with CFRP sheets," Construction and Building Materials, vol. 17, pp. 15-26, 2003.

[33] G. Monti and M. A. Liotta, "Tests and design equations for FRPstrengthening in shear," Construction and Building Materials, vol. 21, pp. 799-809, 2007.

[34] C. Pellegrino and C. Modena, "Fiber Reinforced Polymer Shear Strengthening of Reinforced Concrete Beams with Transverse Steel Reinforcement," Journal of Composites for Construction, vol. 6, pp. 104-111, 2002.

[35] J. F. Chen and J. G. Teng, "Shear capacity of FRP-strengthened RC beams: FRP debonding," Construction and Building Materials, vol. 17, pp. 27-41, 2003.

[36] A. Li, C. Diagana, and Y. Delmas, "Shear strengthening effect by bonded composite fabrics on RC beams," Composites Part B: Engineering, vol. 33, pp. 225-239, 2002.

[37] S. Cao, J. Chen, J. Teng, Z. Hao, and J. Chen, "Debonding in RC beams shear strengthened with complete FRP wraps," Journal of Composites for Construction, vol. 9, pp. 417-428, 2005.

[38] M. Arduini and A. Nanni, "Parametric study of beams with externally bonded FRP reinforcement," ACI Structural Journal, vol. 94, 1997.

[39] A. K. Y. Hii and R. Al-Mahaidi, "Experimental Investigation on Torsional Behavior of Solid and Box-Section RC Beams Strengthened with CFRP Using Photogrammetry," Journal of Composites for Construction, vol. 10, pp. 321-329, 2006.

[40] H. Ronagh, M. Ameli, and P. Dux, "Experimental investigations on FRP strengthening of beams in torsion," in FRP Composites in Civil Engineering - CICE 2004, ed: Taylor \& Francis, 2004, pp. 587-592.

[41] T. D. G. Rao and D. R. Seshu, "Torsion of steel fiber reinforced concrete members," Cement and Concrete Research, vol. 33, pp. 1783-1788, 2003.

[42] A. Hii and R. Al-Mahaidi, "Torsional Capacity of CFRP Strengthened Reinforced Concrete Beams," Journal of Composites for Construction, vol. 11, pp. 71-80, 2007.

[43] C. Tudu, "Study of torsional behaviour of rectangular reinforced concrete beams wrapped with GFRP," 2012.

[44] M. Ameli, H. R. Ronagh, and P. F. Dux, "Behavior of FRP strengthened reinforced concrete beams under torsion," Journal of Composites for Construction, vol. 11, pp. 192-200, 2007.

[45] O. Chaallal, M. J. Nollet, and D. Perraton, "Shear strengthening of RC beams by externally bonded side CFRP strips," Journal of Composites for Construction, vol. 2, pp. 111-113, 1998.

[46] N. S. M. Imran, I. Akbar, T.Ayub., "Literature Review of RC beams Strengthened for Flexure, Shear and Torsion Loading," in International Conference on Civil, Offshore and Environmental Engineering (ICCOEE 2012) 2012.

[47] A. Li, J. Assih, and Y. Delmas, "Shear strengthening of RC beams with externally bonded CFRP sheets," Journal of Structural Engineering, vol. 127, pp. 374-380, 2001.

[48] D. Kachlakev and D. D. McCurry, "Behavior of full-scale reinforced concrete beams retrofitted for shear and flexural with FRP laminates," Composites Part B: Engineering, vol. 31, pp. 445452, 2000.

[49] A. A. El-Ghandour, "Experimental and analytical investigation of CFRP flexural and shear strengthening efficiencies of RC beams," Construction and Building Materials, vol. 25, pp. 1419-1429, 2011.
A. Deifalla and A. Ghobarah, "Strengthening RC T-Beams Subjected to Combined Torsion and Shear Using FRP Fabrics: Experimental Study," Journal of Composites for Construction, vol. 14, pp. 301-311, 2010.

[51] M. C. Sundarraja and S. Rajamohan, "Strengthening of RC beams in shear using GFRP inclined strips - An experimental study," Construction and Building Materials, vol. 23, pp. 856-864, 2009.

[52] S. S. Pendhari, T. Kant, and Y. M. Desai, "Application of polymer composites in civil construction: A general review," Composite Structures, vol. 84, pp. 114-124, 2008.

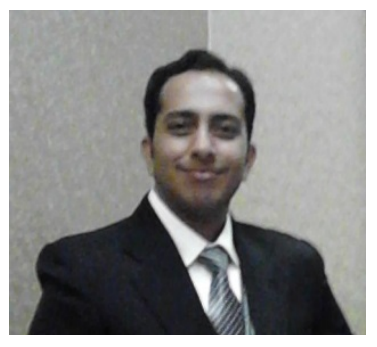

Mr Muhammad Imran was born in Karachi, Pakistan in 1984. Mr. M. Imran received BS in Civil Engineering degree in 2009 from Sir Syed University of Engineering \& Technology in Karachi, Pakistan. Mr M. Imran is currently doing his MS (Civil Engineering) from Universiti Teknologi PETRONAS Perak, Malaysia and also has good civil engineering background.

He has three years of working experience as a Structural Design Engineer in Karachi, Pakistan. He has designed more than twenty structures in different cities of Pakistan. His area of interest is Structure Designing. His current research is on strengthening of Reinforced Concrete (RC) structures especially strengthening of RC Beams using CFRP. His recent research papers are:

1) A Review of Combined Flexure, Shear \& Torsion Strengthening of Reinforced Concrete Beam: ACE-2013 Singapore.

2) A Review of RC Beams Strengthened for Flexure, Shear and Torsion Loading: ICCOEE-2012 Kuala Lumpur Malaysia. 